activity of the night-sky light, as already defined, and the concurrent magnetic activity, expressed as the product $H^{\prime} . \Delta H$, recorded at Mount Wilson 300 miles south-east of Mount Hamilton. Although the correlation between the two curves is less pronounced, and the earlier measures form interlocking points, the point-to-point correspondence is again evident. The coefficients of correlation, referred to the same periods of time as in the previous comparison, are +0.18 and +0.11 respectively. The much lower values of $r$ may, in part, be accounted for by the fact that measures of activity involve observation of the rather rapid fluctuations in sky brightness that are likely to be influenced by localized meteorological conditions. Further, the plots of magnetic activity were derived from measures of $H$ obtained at intervals of time comparable with those of the photometric records. In the circumstances a high degree of correlation would appear improbable.

The results of the foregoing comparisons furnish evidence regarding the reality of the suspected connexion between the two geocosmic phenomena under discussion. They indicate that the level of luminosity of the night sky is determined by the degree of solar ionization established during the hours of daylight, and that the relatively frequent, irregular fluctuations of luminosity which are observed to occur during the night can be attributed, in some measure, to the same agency as that responsible for the concomitant magnetic disturbance.

The general nature of this relationship is further corroborated by the close correspondence revealed by comparisons of the seasonal and diurnal trends in nocturnal luminosity with those of magnetic activity. The results of this latter investigation are presented elsewhere ${ }^{5}$.

Further research, using a photo-electric technique, which is now in progress, aims at an extension of the comparative analysis to measures of nocturnal radiation in other spectral regions.

\footnotetext{
${ }^{1}$ Chapman, S., Phil. Mag.,23, 657 (1937) ; Dauvillier, A., Rev. gén. d'élect., 31, 303, 443, 477 (1932).

${ }^{2}$ Chapman, S., Nature, 121, 989 (1928).

${ }^{3}$ Lord Rayleigh and Jones, H. S., Proc. Roy. Soc. A, ,151, 22 (1935).

- Pub. Ast. Soc. Pac., 52, 319 (1940).

- Lick Obs. Bull., 505 (1941), in the Press.
}

\title{
SPIRITUS VITALIS
}

$\mathrm{D}^{\mathrm{t}}$ URING the past ten years evidence has been accumulating that the reduction of carbon dioxide, a process widely thought of as unique to green plants, may actually be a characteristic of many and widespread organisms and perhaps indeed of universal distribution in living cells. Much of this evidence has been brought together by J. W. Foster, S. F. Carson and S. Ruben (Chronica Botanica, 6, No. $15,337: 1941)$ in an instructive article under the above title and with a useful list of key references.

In addition to the well-known cases of chemosynthesis introduced by Winogradski (for example, sulphur bacteria, nitrifying bacteria) it is now recognized that some purple bacteria absorb carbon dioxide in light in the presence of sulphuretted hydrogen (Thiorhodaceæ, differing therefore from sulphur-bacteria in the need for light) or of organic compounds (Athiorhodaceæ). Similarly the organism responsible for methane production reduces carbon dioxide in the presence of hydrogen, propionic bacteria reduce carbon dioxide during the fermentation of glycerol and other substrates, and the anærobic spore former (Clostridium sp.) isolated by Wieringa in 1936 synthesizes acetic acid from carbon dioxide with gaseous hydrogen as the sole reducing agent. There has been sporadic mention of the fact that carbon dioxide is necessary in small amounts for the development of a number of heterotrophic bacteria, for yeast and for other fungi some of which can be stimulated to more rapid growth in the presence of carbon dioxide at concentrations higher than in normal air. Consideration of the facts relating to pigmented cells led van Niel to propose a generalized formula for photosynthesis :

$$
2 \mathrm{H}_{2} \mathrm{~A}+\mathrm{CO}_{2}=\left(\mathrm{CH}_{2} \mathrm{O}\right)+\mathrm{H}_{2} \mathrm{O}+2 \mathrm{~A},
$$

the hydrogen donor being considered as water in green plants (substantiated by Ruben et al. in 1941 using heavy oxygen), sulphuretted hydrogen in green bacteria, sulphuretted hydrogen and other re- duced sulphur compounds for purple sulphur bacteria, and an analogous formula would seem to apply to most carbon dioxide reductions by organisms. Thus $B$. coli contains an enzyme 'hydrogenlyase' which catalyses the reaction

$$
\mathrm{HCOOH} \rightarrow \mathrm{CO}_{2}+\mathrm{H}_{2} \text {. }
$$

Another organism catalyses the same reaction but reunites the gases to form methane under the influence of 'hydrogenase'. In this it resembles the classical methane fermentation and here, according to van Niel, the hydrogen comes from any oxidizable organic substrate acting as hydrogen donor, with the general relation

$$
4 \mathrm{H}_{2} \mathrm{~A}+\mathrm{CO}_{2}=4 \mathrm{~A}+\mathrm{CH}_{1}+2 \mathrm{H}_{2} \mathrm{O} \text {. }
$$

This and other systems are examined briefly in the review.

In the bulk of these cases the overall metabolism is such that a net uptake of carbon dioxide occurs. The situation in the case of heterotrophic organisms is complicated by the fact that a net production occurs. These have now been investigated using radioactive carbon, and a number of tissues and organisms of different physiological types, both plant and animal, are now known to absorb carbon dioxide. It is finally pointed out that the application of this new method to normal photosynthesis in green plants proves carbon dioxide to be absorbed in darkness, and has suggested that the first intermediate in the photosynthetic process is a large molecule (mol. wt. approx. 1,000) with a free - $\mathrm{COOH}$ and an $\alpha-\mathrm{OH}$. This is conceived as an enzyme or its prosthetic group and suggests that the following reaction occurs:

$$
\mathrm{RH}+\mathrm{CO}_{2} \rightarrow \mathrm{RCOOH} \text { : }
$$

$$
\mathrm{RCOOH}+\mathrm{H}_{2} \mathrm{O}+h \mathrm{v} \rightarrow \mathrm{RCH}_{2} \mathrm{OH}+\mathrm{O}_{2} \text {. }
$$

$\mathrm{RCH}_{2} \mathrm{OH}$ adds another carbon dioxide and the process continues until long carbohydrate chains are built up and split off as starch or soluble sugars. 